Review Article

\title{
Total Ischemic Time as an Independent Predictor of Response to Stem Cell Therapy in Patients with ST Segment Elevation Myocardial Infarction
}

\author{
Mary Lim, ${ }^{1}$ Zekeriya Arslan, ${ }^{2,3}$ Chunyan Cai, ${ }^{4}$ Christopher Y. Kim, ${ }^{2,5}$ \\ Yong-Jian Geng, ${ }^{2}$ and Ali E. Denktas ${ }^{2}$ \\ ${ }^{1}$ Department of Internal Medicine, University of Texas Health Science Center at Houston, Houston, TX 77030, USA \\ ${ }^{2}$ Division of Cardiovascular Medicine, University of Texas Health Science Center at Houston, Houston, TX 77030, USA \\ ${ }^{3}$ Cardiology Service, Ankara Mevki Military Hospital, 06110 Ankara, Turkey \\ ${ }^{4}$ Center for Clinical and Translational Sciences, University of Texas Health Science Center at Houston, Houston, TX 77030, USA \\ ${ }^{5}$ Utah Cardiology PC, Layton, UT 84041, USA
}

Correspondence should be addressed to Zekeriya Arslan; zekeriya.arslan@gmail.com

Received 5 November 2013; Accepted 27 November 2013; Published 16 January 2014

Academic Editors: F. Fagioli, U. Galderisi, K. Guan, I. E. Hoefer, and P. P. Young

Copyright (C) 2014 Mary Lim et al. This is an open access article distributed under the Creative Commons Attribution License, which permits unrestricted use, distribution, and reproduction in any medium, provided the original work is properly cited.

\begin{abstract}
The selection criteria for bone marrow stem cell (BMSC) therapy are not well established for ST segment elevation myocardial infarction (STEMI) patients. This investigation seeks to utilize total ischemic time (TIT), time of symptom onset to percutaneous coronary intervention (PCI), as a criterion for giving BMSC to STEMI patients. A meta-analysis and metaregression were conducted to evaluate improvement of LVEF with BMSC and its association with TIT ( $<6$ and $\geq 6$ hours) and baseline LVEF $(<45 \%$ and $\geq 45 \%)$ at short (3-6 months) and long term ( $>6$ months) followup. At short term, BMSC allowed improvement of LVEF with prolonged TIT (6.62\%, 95\% CI, 2.26 to 10.98 for $<45 \%$; 6.13\%, 95\% CI, 2.59 to 9.67 for $\geq 45 \%$ ). Similarly, for long term, receiving BMSC allowed significant improvement of LVEF for prolonged TIT (9.19\%, 95\% CI, 2.34 to 16.05 for $<45 \%$; 7.64\%, 95\% CI, 3.72 to 11.56 for $\geq 45 \%$ ). Additionally, TIT was a significant predictor of LVEF improvement independent of baseline LVEF in both short (4.96\%, 95\% CI, 0.72 to $9.19, P=0.02)$ and long term $(6.24 \%, 95 \% \mathrm{CI}, 0.46$ to $12.02, P=0.03)$ followup. Consequently, BMSC therapy allows LVEF improvement in prolonged TIT and future studies for BMSC should include TIT $\geq 6$ hours as an inclusion criterion.
\end{abstract}

\section{Introduction}

Autologous bone marrow stem cell (BMSC) injection in patients with ST segment elevation myocardial infarction (STEMI) has been investigated as a new treatment strategy for the past decade. After the first encouraging pilot study [1] in 2002, many trials have since been published. Although several studies failed to show any favorable outcomes from BMSC [2-5], there have been many trials which demonstrated the beneficial effects of BMSC [6-12]. Several meta-analyses have confirmed that BMSC injections improved left ventricular systolic function, on average, by 3\% [13-15]. Despite the promising results in these studies, there were many inconsistencies in the selection criteria; incongruent cell types, varying administration time, and variable injection routes are a few examples. Selected patients were also heterogeneous in terms of baseline left ventricular ejection fraction (LVEF) and time from symptom onset to reperfusion. Unfortunately, it is still difficult to identify the best model to demonstrate the effectiveness of stem cell therapy.

In this study, we attempted to define an independent parameter which can increase the efficacy of BMSC: we focused on whether the total ischemic time (TIT), defined by the time of symptom onset to the time of percutaneous coronary intervention (PCI), was associated with LVEF improvement in response to BMSC administration in STEMI patients. 


\section{Methods}

2.1. Study Selection Criteria. The study selection criterion was adapted from Zhang et al. [13], and it aimed to investigate the effect of BMSC administration on LVEF improvement as a function of total ischemic time and baseline LVEF.

2.1.1. Inclusion Criteria. Studies that included STEMI patients who had PCI performed within 12 hours of symptom onset and BMSC treatment. Studies which were included were either randomized or placebo controlled trials, having at least 10 patients in each respective trial and a reported clinical endpoint of LVEF improvement. Only English language literature was searched.

2.1.2. Exclusion Criteria. Greater than 12 hours of symptom onset to PCI, reperfusion other than PCI, BMSC delivery other than intracoronary cell delivery (e.g., intramyocardial, peripheral blood, etc.), use of stem cells other than BMSC, and the use of granulocyte colony-stimulating factor to induce BMSC release. Nonrandomized or noncontrolled trials, and trials with less than 10 patients in each respective study were also excluded.

2.2. Data Search. We performed a systematic literature search for randomized controlled clinical trials evaluating BMSC effects on LVEF and left ventricular end systolic volume (LVESV) in STEMI patients who underwent PCI. PubMed, Ovid's MEDLINE, and Cochrane Evidence-Based Medicine (EBM) Reviews databases from January 1990 through August 2010 were searched to identify all eligible trials by using the following medical subject heading $(\mathrm{MeSH})$ terms and text words: bone marrow, stem cell, progenitor cells, cell transplantation, cell therapy, myocardial infarction, and cardiac repair. Additionally, the reference lists of reviews were searched for all relevant studies.

2.3. Study Enrollment and Data Extraction. Data for LVEF, LVESV, and major adverse cardiovascular events (MACE) were extracted and checked by three investigators according to our inclusion criteria and classified as short term (3 to 6 months) and long term (>6 months) according to follow-up periods. Left ventricular performance parameters were extracted from the magnetic resonance imaging (MRI) results, if they existed. Otherwise, echocardiograph (Echo), angiographic (Angio), and/or single photon emission computed tomography (PET) results were taken, respectively.

2.4. Data Synthesis and Statistical Analyses. For statistical analysis, STATA 11 software (StataCorp, College Station, TX) and R (Development Core Team, Version 3.0.0) were used. $P$ values $<0.05$ were considered statistically significant.

Meta-analysis [24-26] was conducted to evaluate the overall BMSC effect by comparing the mean difference between the BMSC and placebo group. Fixed and random effects model were performed according to the overall heterogeneity, which was examined with $I^{2}$ and Cochran's chisquare test. The inverse variance method was applied to weigh the mean difference of each included study.

For analysis on LVEF, mean difference between the BMSC and placebo group, $\mathrm{LVEF}_{\text {change, }}$ and their $95 \%$ confidence interval $(\mathrm{CI})$ were calculated. In particular, $\mathrm{LVEF}_{\text {change }}=$ $\mathrm{LVEF}_{\text {BMSCchange }}-\mathrm{LVEF}_{\text {Placebochange, }}$, where $\mathrm{LVEF}_{\text {BMSCchange }}$ and $\mathrm{LVEF}_{\text {Placebochange }}$ are the mean change of the LVEF from the baseline in the BMSC and placebo group, respectively. Most of the studies reported the mean and standard deviation (SD) for $\operatorname{LVEF}_{\text {BMSCchange }}$ and $\mathrm{LVEF}_{\text {Placebochange. For those }}$ studies in which the mean and SD were missing, an estimation was made of the mean and SD based on the reported mean and SD of LVEF at baseline, during followup, and the estimated correlation coefficient between the baseline and follow-up LVEF within each group [27]. The reported values in Schächinger et al. [8] and Yousef et al. [22] were utilized to estimate the correlation coefficients, within each group, for short and long term followup, respectively. Similarly, the mean difference of LVESV, LVESV ${ }_{\text {change, }}$ and its 95\% CI were evaluated. The weighted mean difference (WMD) was reported for each study and the statistical significance of the overall effect of all studies was performed by $z$ test.

If the significance of heterogeneity was found, a metaregression analysis was performed to assess the relationship between $\mathrm{LVEF}_{\text {change }}$, TIT ( $<6$ hours versus $\geq 6$ hours), and baseline LVEF prior to PCI ( $<45 \%$ versus $\geq 45 \%$ ).

For the MACE data set, the number of patients $(n)$ who had cardiovascular deaths, rehospitalization in the form of heart failure (HF) or myocardial infarction (MI), or ventricular arrhythmias was modeled by the meta-analysis based on the Mantel-Haenszel method. The risk ratio (RR) and the $95 \%$ CI were calculated.

\section{Results}

3.1. Selected Studies and Characteristics. Five hundred fortyseven studies were identified from the electronic databases. After exclusion of duplicated or nonrelated articles, 43 papers were saved as references. Twenty-seven of these were excluded based on the exclusion criteria.

For LVEF data, a total of 20 articles reporting the results of 14 trials (13 trials with 855 patients for short term, and 7 trials with 466 patients for long term) were included in this study. Six articles in the long term group had the results of the same studies of those in the short term category $[5,16,18,20$, 21, 23]. Eighteen trials contained LVESV data; four of them were excluded because the results were reported as LVESV index. For MACE analysis, we used 10 trials for the short term and 6 trials in the long term analysis. Additionally, in order to remove the effects of an outlier, we excluded one study [28] (since its mean PCI time was 20 hours) because this severely prolonged ischemic time left little hope for beneficial effects from PCI.

The characteristics of the studies, including patient number, follow-up months, TIT, and the method of LVEF 


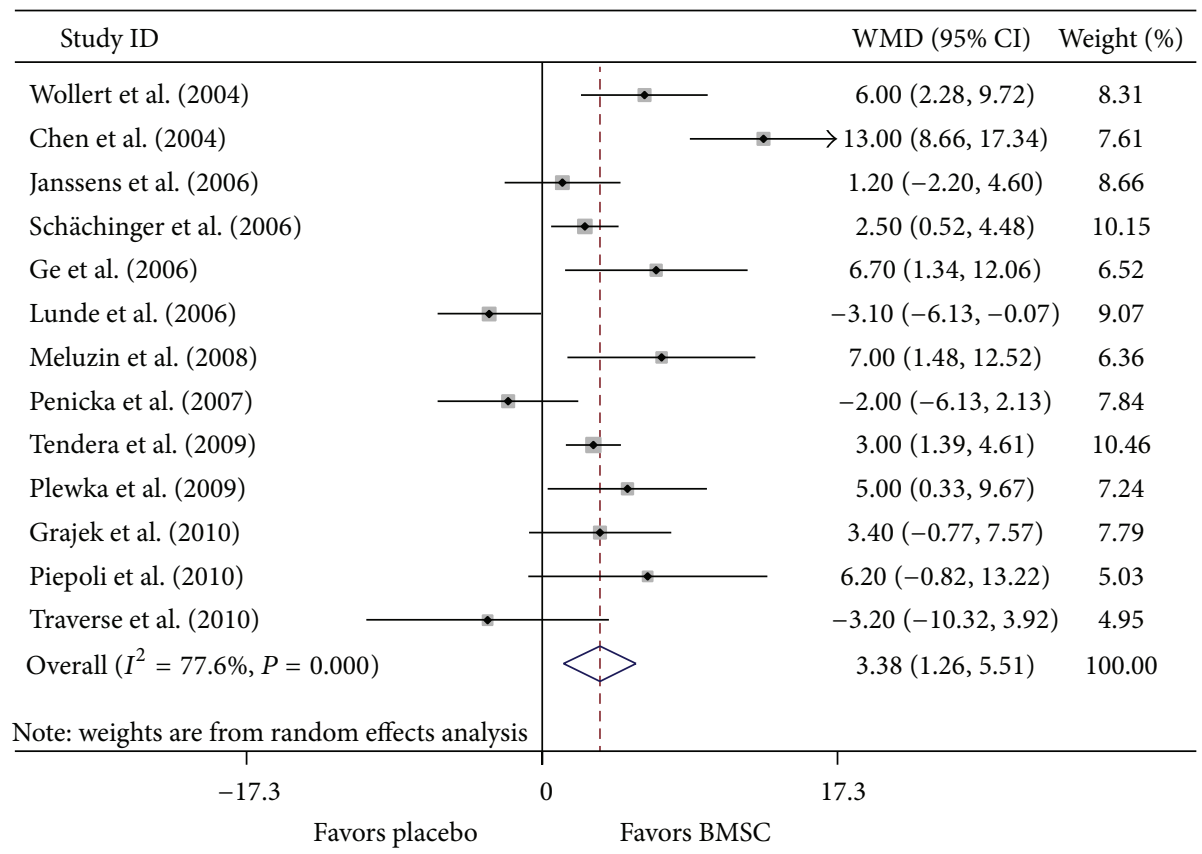

(a)

\begin{tabular}{|c|c|c|c|}
\hline Study ID & & WMD $(95 \% \mathrm{CI})$ & Weight (\%) \\
\hline Meyer et al. (2006) & 1 & $2.80(-1.88,7.48)$ & 13.77 \\
\hline Meluzin et al. (2008) & & $7.00(1.48,12.52)$ & 12.88 \\
\hline Beitnes et al. (2009) & - & $-1.60(-4.27,1.07)$ & 15.67 \\
\hline Yousef et al. (2009) & $\longrightarrow$ & $10.40(8.48,12.32)$ & 16.18 \\
\hline Grajek et al. (2010) & $\frac{1}{1}$ & $3.10(-0.12,6.32)$ & 15.20 \\
\hline Assmus et al. (2010) & $\rightarrow$ & $9.80(7.14,12.46)$ & 15.67 \\
\hline Piepoli et al. (2010) & . & $\rightarrow 6.00(-1.61,13.61)$ & 10.64 \\
\hline Overall $\left(I^{2}=90.6 \%, P=0.000\right)$ & & $5.36(1.26,9.47)$ & 100.00 \\
\hline Note: weights are from random effects analysis & $s$ & & \\
\hline-13.6 & 0 & 13.6 & \\
\hline Favors placebo & Favors BMSC & & \\
\hline
\end{tabular}

(b)

FIGURE 1: Forest plot of WMD with 95\% CI on LVEF demonstrated favorable LVEF outcomes within the BMSC group compared with the placebo group. The size of data markers represents the statistical weight of each included study before it was pooled to the overall effect. (a) Trials in short term followup: heterogeneity: $\chi^{2}=53.63, \mathrm{df}=12, P<0.0001$, and $I^{2}$ (variation in WMD attributable to heterogeneity) $=77.6 \%$. (b) Trials in long term followup: heterogeneity: $\chi^{2}=63.86, \mathrm{df}=6, P<0.0001$, and $I^{2}$ (variation in WMD attributable to heterogeneity) $=$ $90.6 \%$.

measures are summarized in Table 1 . The baseline and postPCI measurements of left ventricular parameters, as well as MACE, are shown in Table 2. The mean values for the baseline LVEF and LVESV between the BMSC and placebo group are grossly similar, with a range of $0-4.4 \%$ and $0-8 \mathrm{~mL} / \mathrm{m}^{2}$, respectively. In Table 3, the studies are separated into short or long term followup and categorized based on their subgroup characteristics, as defined by TIT ( $<6$ hours or $\geq 6$ hours) and baseline LVEF prior to PCI $(<45 \%$ or $\geq 45 \%)$.
3.2. Effect on LVEF. Cochran's chi-square test for heterogeneity suggested significance on $\mathrm{LVEF}_{\text {change }}$ for both short term $(P<0.0001)$ and long term followup $(P<0.0001)$ (Figure 1$)$. Therefore, a meta-analysis based on a random effects model was performed to obtain the overall LVEF improvement within the BMSC group compared with placebo. The overall LVEF improvement demonstrated significant difference between the BMSC and placebo group, favoring the BMSC category with a mean difference of $3.38 \%$ (95\% CI, 1.26 to 5.51 , 
Short term LVEF difference after PCI

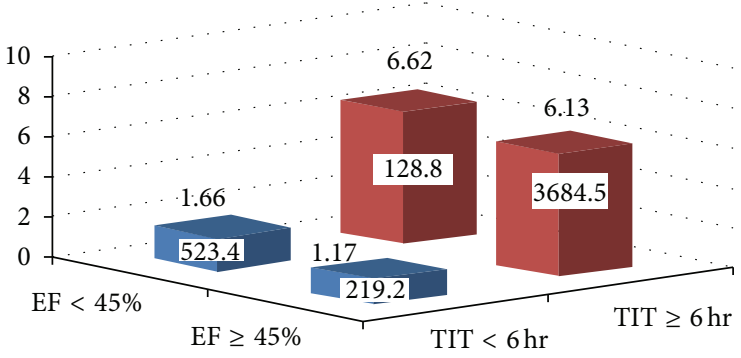

(a) Short term followup
Long term LVEF difference after PCI

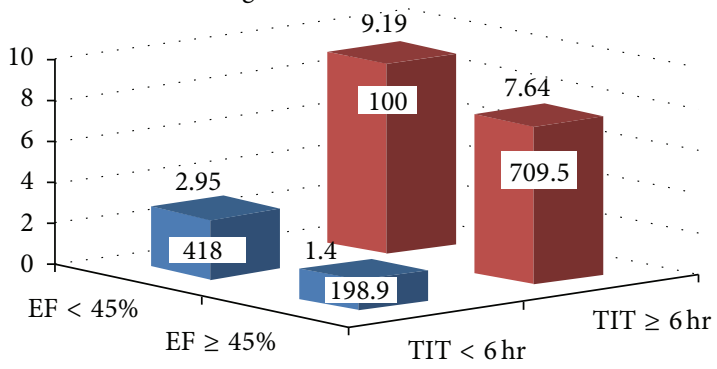

(b) Long term followup

FIGURE 2: The difference in LVEF between the BMSC and placebo group after PCI.

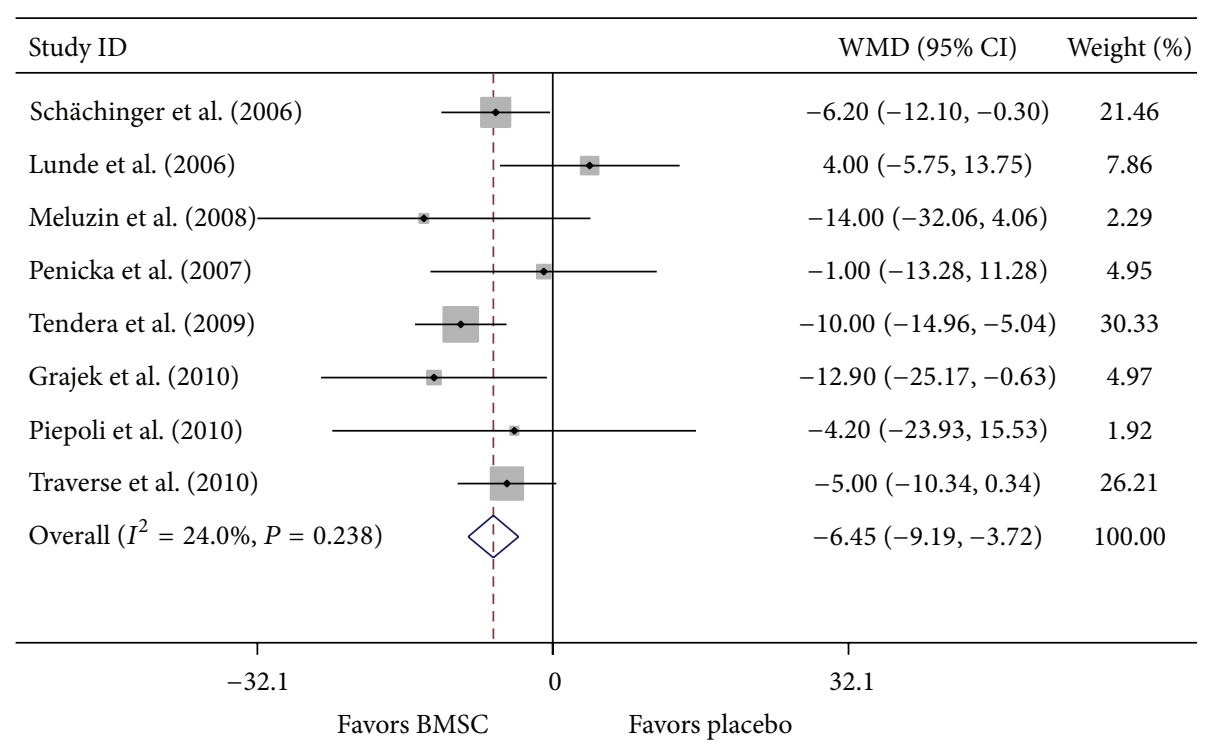

(a)

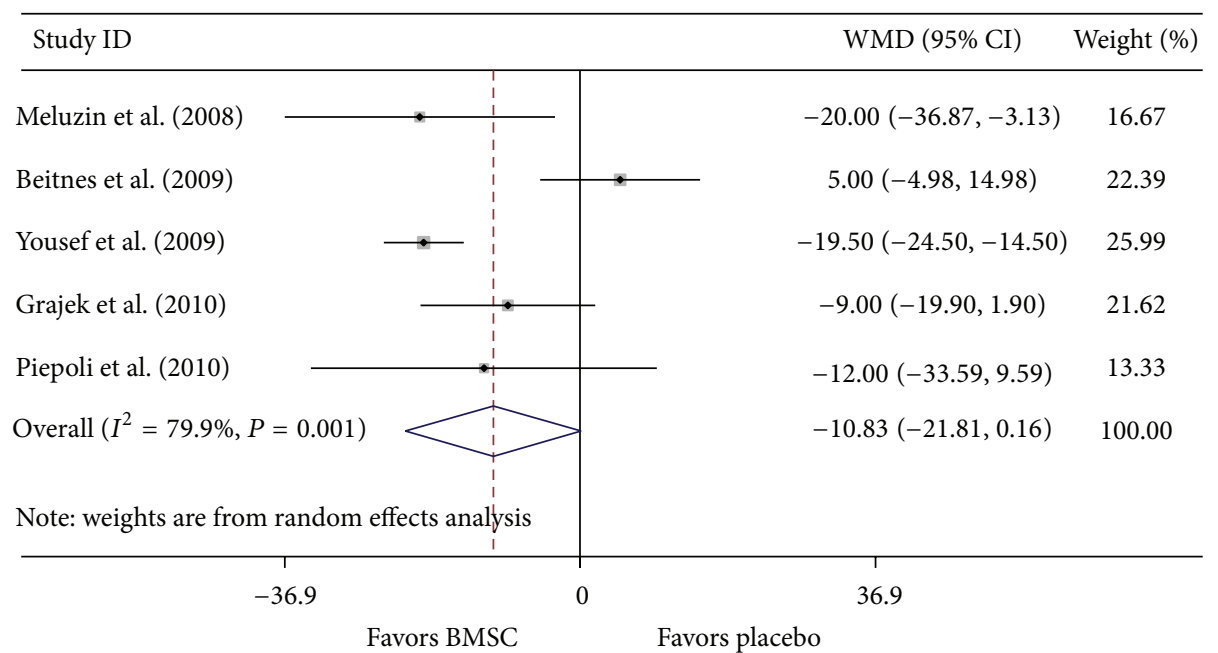

(b)

FIGURE 3: Forest plot of WMD with 95\% CI on LVESV demonstrated favorable outcomes within the BMSC group compared with the placebo. The size of data markers represents the statistical weight of each included study before it was pooled to the overall effect. (a) Trials in short term followup: heterogeneity: $\chi^{2}=9.21, \mathrm{df}=7, P=0.238$, and $I^{2}$ (variation in WMD attributable to heterogeneity) $=24 \%$. (b) Trials in long term followup: heterogeneity: $\chi^{2}=19.9, \mathrm{df}=4, P=0.0005$, and $I^{2}$ (variation in WMD attributable to heterogeneity) $=79.9 \%$. 


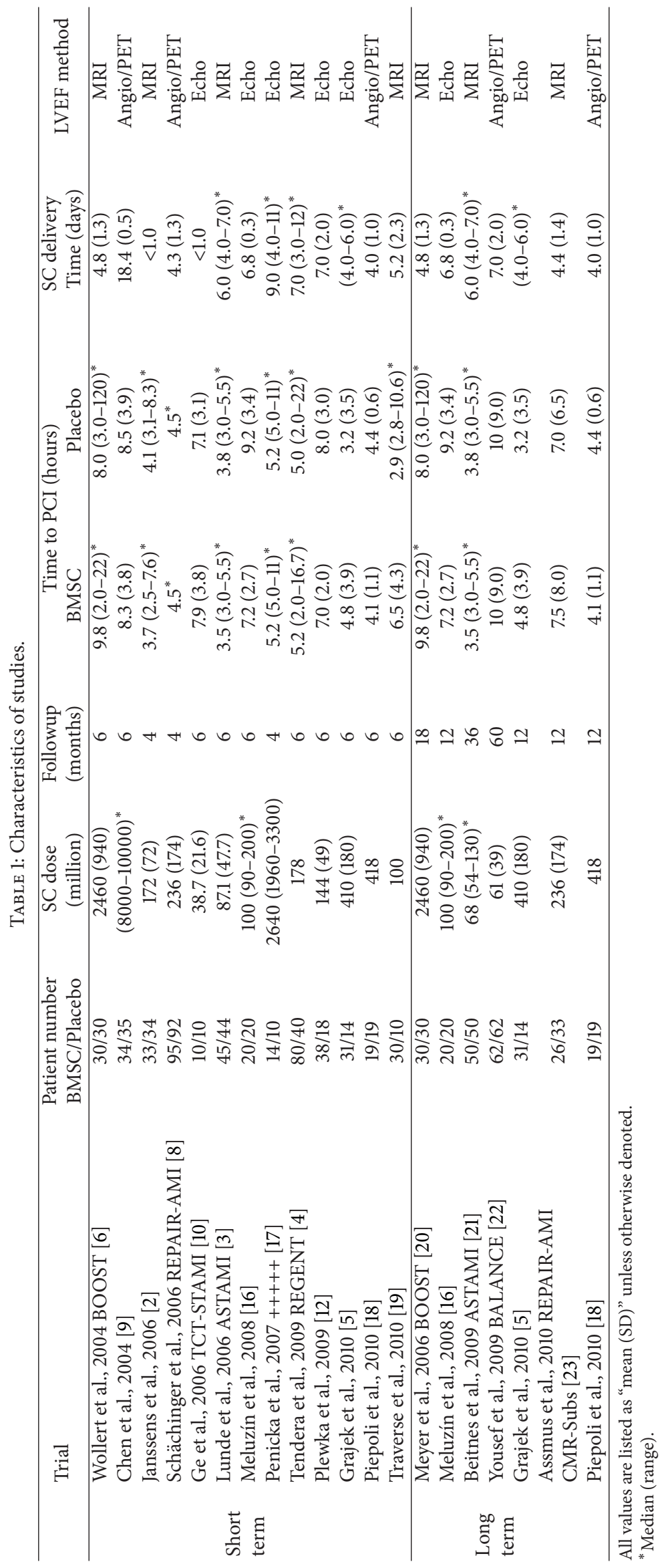




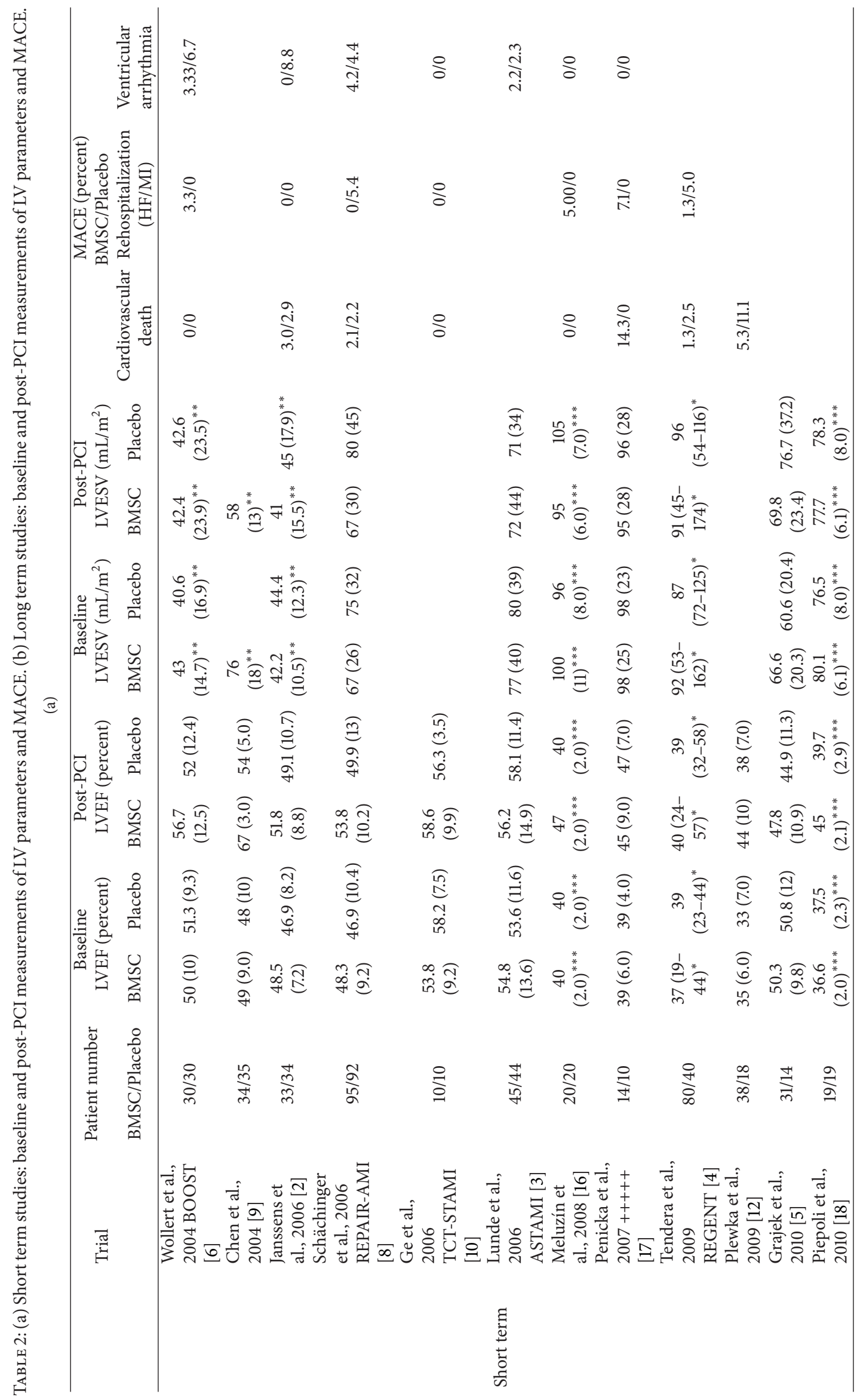




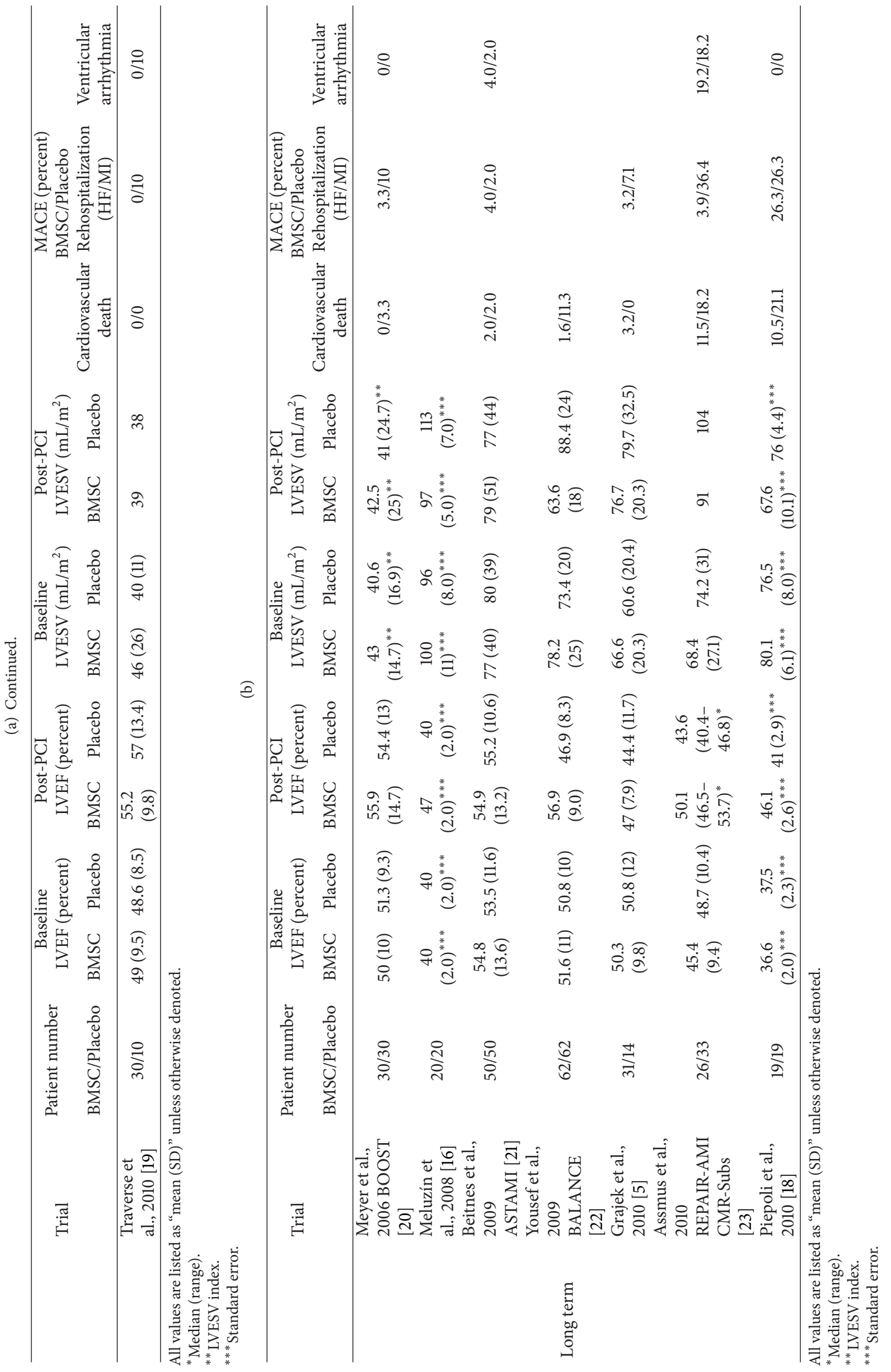




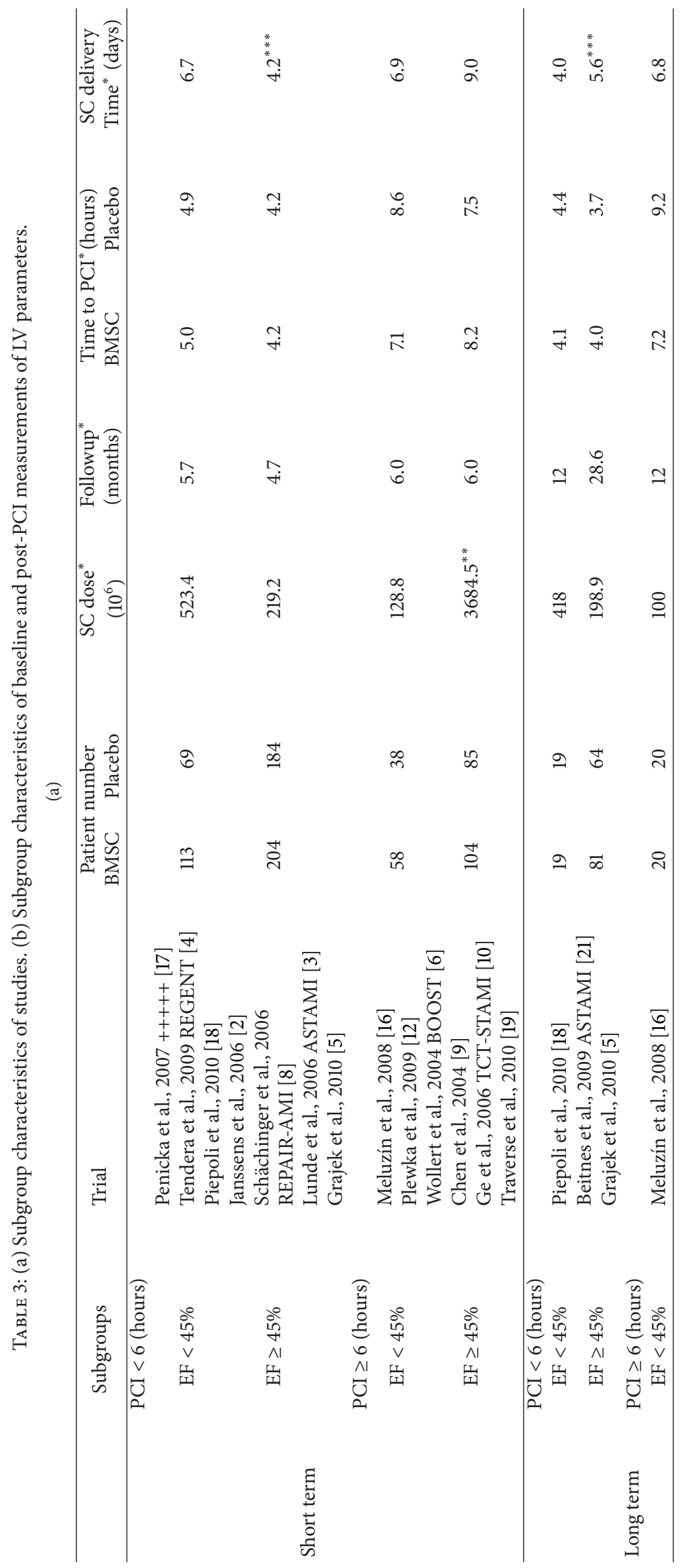




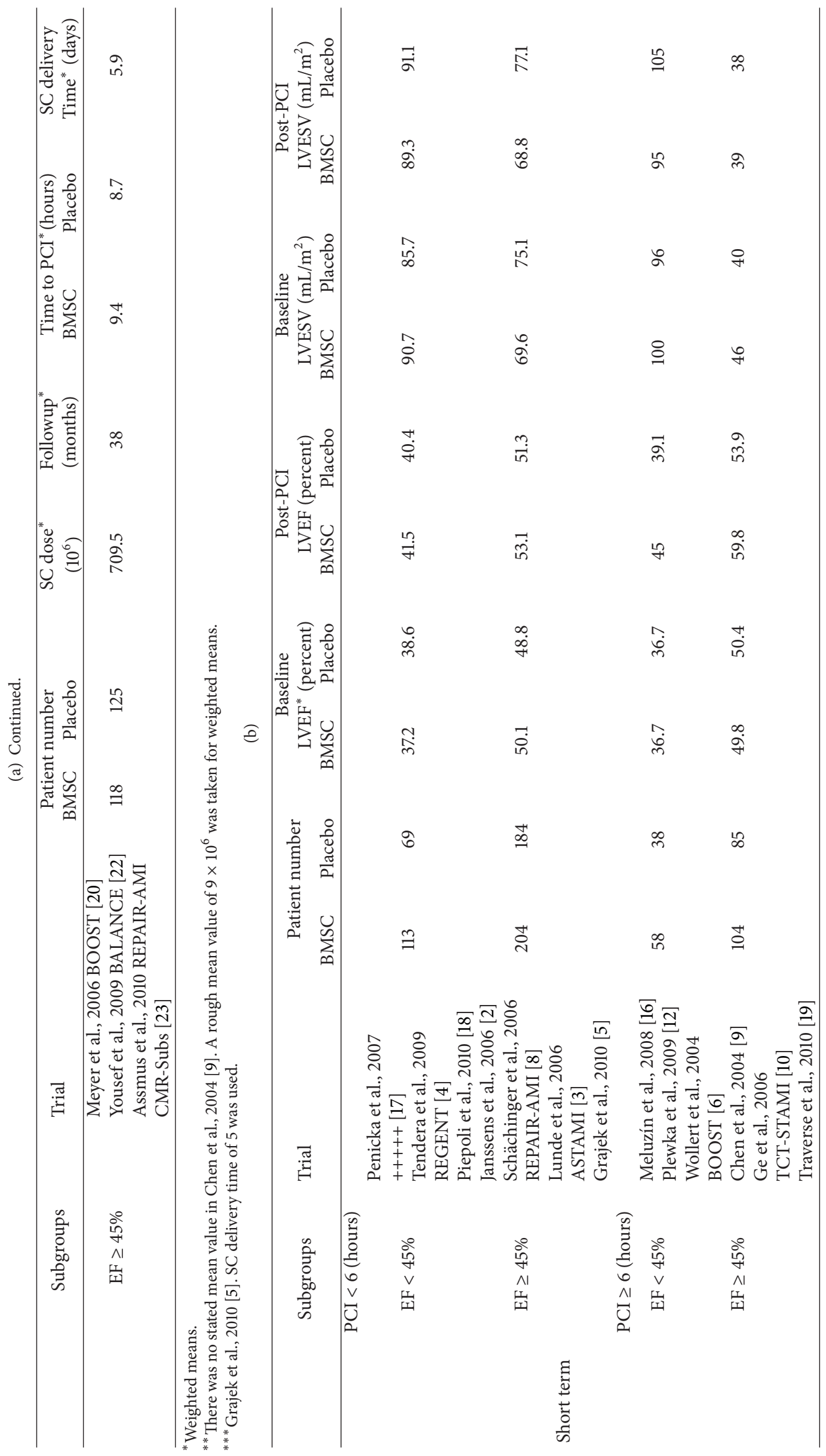




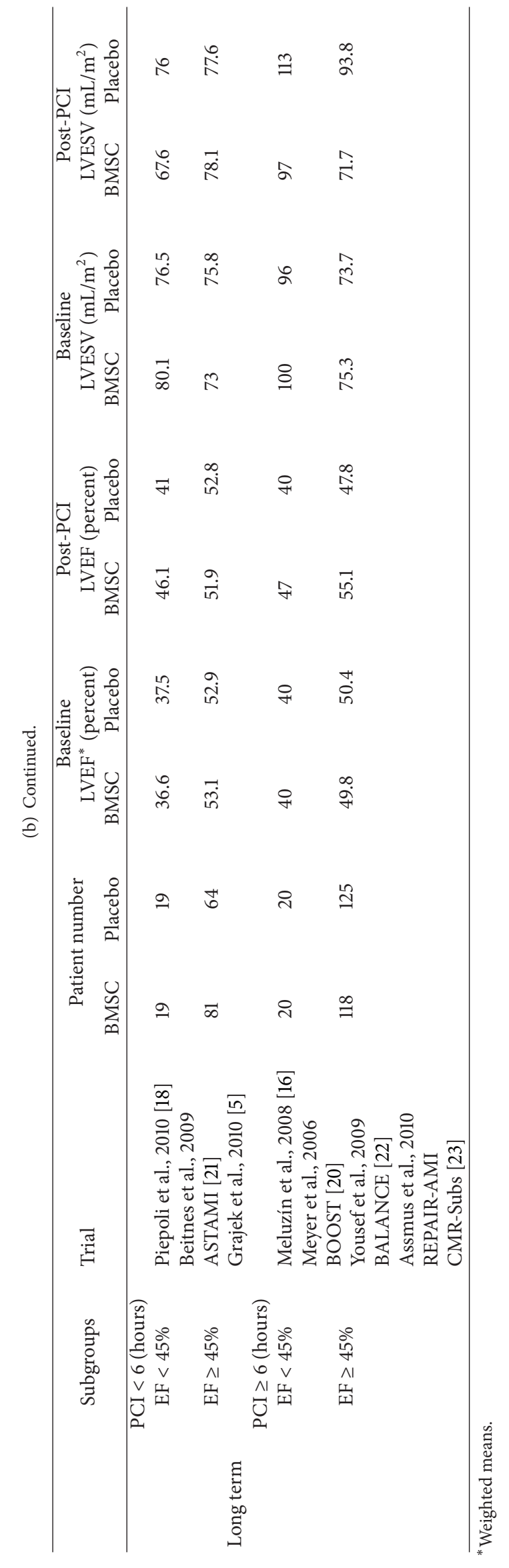




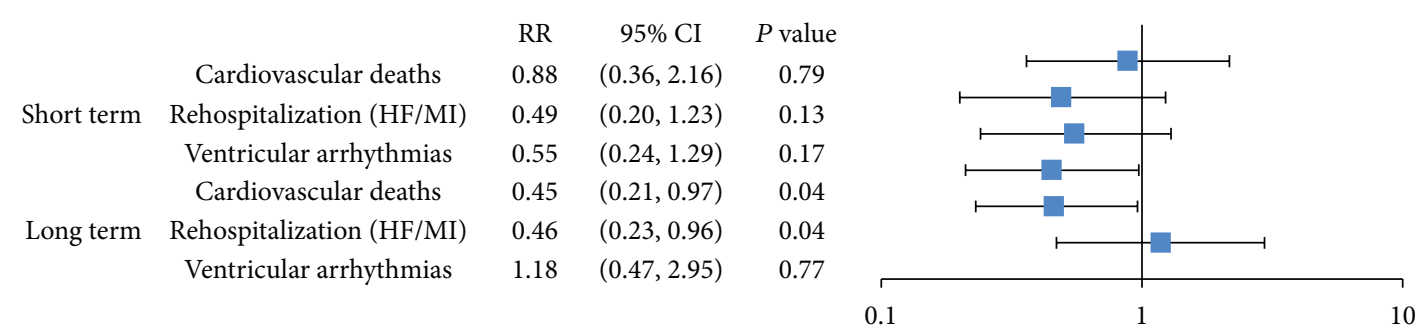

Figure 4: MACE at short term and long term followup.

$P=0.002)$ in the short term and 5.36\% (95\% CI, 1.26 to 9.47 , $P=0.01)$ in the long term followup.

Based on the evidence of heterogeneity on LVEF, a random effects meta-regression model was built to evaluate the relationship between the BMSC effect and two binary covariates (TIT, $<6$ hours or $\geq 6$ hours, and baseline LVEF, $<45 \%$ or $\geq 45 \%$ ).

In the short term followup, patients within the prolonged TIT subgroup exhibited a substantial improvement in LVEF favoring the BMSC category regardless of baseline function (short term: $6.62 \%, 95 \%$ CI, 2.26 to 10.98 for $<45 \%$ and $6.13 \%$, 95\% CI, 2.59 to 9.67 for $\geq 45 \%$; long term: $9.19 \%$, 95\% CI, 2.34 to 16.05 for $<45 \%$ and $7.64 \%, 95 \%$ CI, 3.72 to 11.56 for $\geq 45 \%$ ). Although there was a trend towards improved LVEF for the BMSC group with reduced TIT, the results were not statistically significant (short term: $1.66 \%, 95 \% \mathrm{CI},-2.12$ to 5.44 for $<45 \%$ and $1.17 \%, 95 \%$ CI, -2.02 to 4.36 for $\geq 45 \%$; long term: $2.95 \%, 95 \% \mathrm{CI},-4.29$ to 10.2 for $<45 \%$ and $1.4 \%, 95 \% \mathrm{CI}$, -3.29 to 6.09 for $\geq 45 \%$ ) (Figure 2 ).

For both short and long term followup, the statistical significant regression coefficients suggest that the binary indicator of TIT ( $<6$ hours or $\geq 6$ hours) is an independent predictor affecting the improvement of LVEF when comparing the BMSC to the placebo groups $(4.96 \%, 95 \% \mathrm{CI}, 0.72$ to 9.19, $P=0.02$ and $6.24 \%, 95 \% \mathrm{CI}, 0.46$ to $12.02, P=0.03$, resp.). Although there was no statistical significance, there appeared to be a trend towards improved LVEF for the BMSC category within the LVEF $<45 \%$ subgroup, at short term and long term followup $(0.49 \%, P=0.82$ and $1.55 \%, P=0.67$, resp.).

3.3. Effect on LVESV. Cochran's chi-square test for heterogeneity suggested significance on $\mathrm{LVESV}_{\text {change }}$ for long term $(P<0.0001)$ but not short term followup $(P=0.238)$ (Figure 3). Therefore, a meta-analysis based on fixed effects model and random effects model for short term was performed to obtain the overall LVESV benefits comparing the BMSC to the placebo group. Compared to placebo, the treatment effect of BMSC on LVESV improvement demonstrated a mean difference of $-6.45 \mathrm{~mL} / \mathrm{m}^{2}$ (95\% CI, -9.19 to -3.72 , $P<0.0001)$ in the short term and $-10.83 \mathrm{~mL} / \mathrm{m}^{2}(95 \% \mathrm{CI}$, -21.81 to $0.16, P=0.05)$ in the long term followup. Because of nonsignificance of heterogeneity and the limited number of trials, a meta-regression analysis was not conducted on LVESV for both short term and long term trials.
3.4. Effect on MACE. The RR of MACE between the BMSC and placebo group were calculated. At short term followup, compared with the placebo, there was a trend towards beneficial effects of BMSC against cardiovascular deaths (RR: $0.88,95 \% \mathrm{CI}, 0.36$ to $2.16, P=0.79$ ), rehospitalization from HF or MI (RR: $0.13,95 \% \mathrm{CI}, 0.20$ to $1.23, P=0.13$ ), and ventricular arrhythmias (RR: $0.17,95 \% \mathrm{CI}, 0.24$ to $1.29, P=$ 0.17 ), though these findings were not statistically significant. However, at long term followup, there was statistical significance demonstrating that decreased morbidity and mortality (measured as cardiovascular deaths, RR: 0.45, 95\% CI, 0.21 to $0.97, P=0.04$, and rehospitalization, RR: $0.46,95 \% \mathrm{CI}$, 0.23 to $0.96, P=0.04$ ) were associated with receiving BMSC (Figure 4).

\section{Discussion}

Overall, from the systematic review and meta-regression analysis, the total ischemic time (TIT), defined by the time of symptom onset to the time of percutaneous coronary intervention (PCI), is shown to be a significant factor for LVEF improvement when comparing the BMSC to the placebo group if intervention is performed after 6 hours for both short term and long term followup (Figure 2). Although there was also a trend towards improvement of LVEF with decreased TIT (<6 hours), the data was not statistically significant.

The reason for this effect can be multifactorial; it is our belief that with TIT $<6$ hours, the rapid restoration of blood flow to the infarcted artery will reduce the damage to the myocardium, thus limiting the potential for benefit with the administration of BMSC. Accordingly, Denktas et al. [29] demonstrated that for patients presenting with STEMI, a TIT of less than 120 minutes allows for improved clinical outcomes because of reduced infarct size. Therefore, it is possible that the beneficial effects of BMSC will be masked for the subgroup of people who present with reduced TIT. Another potential reason that there was no statistical significance for LVEF improvement with decreased TIT can be that the patients included in our selected studies who presented with their first STEMI may have already had impaired LV function at baseline, which was not identified prior to their presentation. Thus, the improvement potential of LVEF during followup will be limited in that group of patients despite having a reduced TIT. 
Previous meta-analyses have shown that intracoronary BMSC infusion has beneficial effects on restoration of left ventricular systolic dysfunction after acute STEMI [13-15]; the results from our analysis are consistent with these findings, having a mean LVEF improvement, within the BMSC group, of $3.38 \%$ in the short term, and $5.36 \%$ in the long term followup. Additionally, similar to previous meta-analyses, we found that there was no increase in MACE with BMSC therapy in STEMI patients. On the contrary, there appeared to be evidence in favor of BMSC in the prevention of MACE for cardiovascular deaths and rehospitalization (by HF or MI), especially at long term followup (Figure 4).

Although we have demonstrated the beneficial effects of intracoronary BMSC infusion, a topic of interest (which we did not touch upon) is whether different types of transplanted stem cells will also provide an equivalent improvement in cardiac function for TIT $\geq 6$ hours. Though analyzing the effects of incongruent cell types is out of the realms of the literature review for our paper, this area of research will be a possible topic for further investigation.

In conclusion, patient selection is an important part of ensuring maximal benefit from BMSC treatment. Current studies demonstrate that BMSC therapy can contribute to the improvement of left ventricular systolic function in select patients. More specifically, we found that total ischemic time is an independent predictor of BMSC treatment response in STEMI patients. We therefore propose that the selection criteria for any new trials looking to demonstrate the efficacy of BMSC treatment in STEMI patients should include the total ischemic time, specifically $\geq 6$ hours, as one of the patient selection criteria.

\section{Conflict of Interests}

The authors declare that there is no conflict of interests regarding the publication of this paper.

\section{Acknowledgment}

The authors wish to thank Monir Hossain for his contributions with the preliminary statistical analysis.

\section{References}

[1] B. E. Strauer, M. Brehm, T. Zeus et al., "Repair of infarcted myocardium by autologous intracoronary mononuclear bone marrow cell transplantation in humans," Circulation, vol. 106, no. 15, pp. 1913-1918, 2002.

[2] S. Janssens, C. Dubois, J. Bogaert et al., "Autologous bone marrow-derived stem-cell transfer in patients with ST-segment elevation myocardial infarction: double-blind, randomised controlled trial," The Lancet, vol. 367, no. 9505, pp. 113-121, 2006.

[3] K. Lunde, S. Solheim, S. Aakhus et al., "Intracoronary injection of mononuclear bone marrow cells in acute myocardial infarction," The New England Journal of Medicine, vol. 355, no. 12, pp. 1199-1209, 2006.

[4] M. Tendera, W. Wojakowski, W. Ruyłło et al., "Intracoronary infusion of bone marrow-derived selected CD $34^{+} \mathrm{CXCR} 4^{+}$cells and non-selected mononuclear cells in patients with acute
STEMI and reduced left ventricular ejection fraction: results of randomized, multicentre Myocardial Regeneration by Intracoronary Infusion of Selected Population of Stem Cells in Acute Myocardial Infarction (REGENT) Trial," European Heart Journal, vol. 30, no. 11, pp. 1313-1321, 2009.

[5] S. Grajek, M. Popiel, L. Gil et al., "Influence of bone marrow stem cells on left ventricle perfusion and ejection fraction in patients with acute myocardial infarction of anterior wall: randomized clinical trial," European Heart Journal, vol. 31, no. 6, pp. 691-702, 2010.

[6] K. C. Wollert, G. P. Meyer, J. Lotz et al., "Intracoronary autologous bone-marrow cell transfer after myocardial infarction: the BOOST randomised controlled clinical trial," The Lancet, vol. 364, no. 9429, pp. 141-148, 2004.

[7] J. M. Hare, J. H. Traverse, T. D. Henry et al., "A randomized, double-blind, placebo-controlled, dose-escalation study of intravenous adult human mesenchymal stem cells (prochymal) after acute myocardial infarction," Journal of the American College of Cardiology, vol. 54, no. 24, pp. 2277-2286, 2009.

[8] V. Schächinger, S. Erbs, A. Elsässer et al., "Improved clinical outcome after intracoronary administration of bone-marrowderived progenitor cells in acute myocardial infarction: final 1year results of the REPAIR-AMI trial," European Heart Journal, vol. 27, no. 23, pp. 2775-2783, 2006.

[9] S.-L. Chen, W.-W. Fang, F. Ye et al., "Effect on left ventricular function of intracoronary transplantation of autologous bone marrow mesenchymal stem cell in patients with acute myocardial infarction," American Journal of Cardiology, vol. 94, no. 1, pp. 92-95, 2004.

[10] J. Ge, Y. Li, J. Qian et al., "Efficacy of emergent transcatheter transplantation of stem cells for treatment of acute myocardial infarction (TCT-STAMI)," Heart, vol. 92, no. 12, pp. 1764-1767, 2006.

[11] J. Meluzín, J. Mayer, L. Groch et al., “Autologous transplantation of mononuclear bone marrow cells in patients with acute myocardial infarction: the effect of the dose of transplanted cells on myocardial function," American Heart Journal, vol. 152, no. 5, pp. 975.e9-975.e15, 2006.

[12] M. Plewka, M. Krzemińska-Pakuła, P. Lipiec et al., "Effect of intracoronary injection of mononuclear bone marrow stem cells on left ventricular function in patients with acute myocardial infarction," American Journal of Cardiology, vol. 104, no. 10, pp. 1336-1342, 2009.

[13] S. Zhang, A. Sun, D. Xu et al., "Impact of timing on efficacy and safety of intracoronary autologous bone marrow stem cells transplantation in acute myocardial infarction: a pooled subgroup analysis of randomized controlled trials," Clinical Cardiology, vol. 32, no. 8, pp. 458-466, 2009.

[14] E. Martin-Rendon, S. J. Brunskill, C. J. Hyde, S. J. Stanworth, A. Mathur, and S. M. Watt, "Autologous bone marrow stem cells to treat acute myocardial infarction: a systematic review," European Heart Journal, vol. 29, no. 15, pp. 1807-1818, 2008.

[15] S. Singh, R. Arora, K. Handa et al., "Stem cells improve left ventricular function in acute myocardial infarction," Clinical Cardiology, vol. 32, no. 4, pp. 176-180, 2009.

[16] J. Meluzín, S. Janoušek, J. Mayer et al., "Three-, 6-, and 12month results of autologous transplantation of mononuclear bone marrow cells in patients with acute myocardial infarction," International Journal of Cardiology, vol. 128, no. 2, pp. 185-192, 2008.

[17] M. Penicka, J. Horak, P. Kobylka et al., "Intracoronary injection of autologous bone marrow-derived mononuclear cells 
in patients with large anterior acute myocardial infarction: a prematurely terminated randomized study," Journal of the American College of Cardiology, vol. 49, no. 24, pp. 2373-2374, 2007.

[18] M. F. Piepoli, D. Vallisa, M. Arbasi et al., "Bone marrow cell transplantation improves cardiac, autonomic, and functional indexes in acute anterior myocardial infarction patients (cardiac study)," European Journal of Heart Failure, vol. 12, no. 2, pp. 172-180, 2010.

[19] J. H. Traverse, D. H. McKenna, K. Harvey et al., "Results of a phase 1, randomized, double-blind, placebo-controlled trial of bone marrow mononuclear stem cell administration in patients following ST-elevation myocardial infarction," American Heart Journal, vol. 160, no. 3, pp. 428-434, 2010.

[20] G. P. Meyer, K. C. Wollert, J. Lotz et al., "Intracoronary bone marrow cell transfer after myocardial infarction: eighteen months' follow-up data from the randomized, controlled BOOST (BOne marrOw transfer to enhance ST-elevation infarct regeneration) trial," Circulation, vol. 113, no. 10, pp. 1287$1294,2006$.

[21] J. O. Beitnes, E. Hopp, K. Lunde et al., "Long-term results after intracoronary injection of autologous mononuclear bone marrow cells in acute myocardial infarction: the ASTAMI randomised, controlled study," Heart, vol. 95, no. 24, pp. 19831989, 2009.

[22] M. Yousef, C. M. Schannwell, M. Köstering, T. Zeus, M. Brehm, and B. E. Strauer, "The BALANCE Study: clinical benefit and long-term outcome after intracoronary autologous bone marrow cell transplantation in patients with acute myocardial infarction," Journal of the American College of Cardiology, vol. 53, no. 24, pp. 2262-2269, 2009.

[23] B. Assmus, A. Rolf, S. Erbs et al., "Clinical outcome 2 years after intracoronary administration of bone marrow-derived progenitor cells in acute myocardial infarction," Circulation: Heart Failure, vol. 3, no. 1, pp. 89-96, 2010.

[24] M. Egger, G. D. Smith, and D. G. Altman, Systematic Reviews in Health Care: Meta-Analysis in Context, BMJ Publishing Group, London, UK, 2001.

[25] S. T. Normand, "Meta-analysis: formulating, evaluating, combining and reporting," Statistics in Medicine, vol. 18, pp. 321-359, 1999.

[26] H. Chu, L. Nie, Y. Chen, Y. Huang, and W. Sun, "Bivariate random effects models for meta-analysis of comparative studies with binary outcomes: methods for the absolute risk difference and relative risk," Statistical Methods in Medical Research, vol. 21, no. 6, pp. 621-633, 2010.

[27] D. Follmann, P. Elliott, I. Suh, and J. Cutler, "Variance imputation for overviews of clinical trials with continuous response," Journal of Clinical Epidemiology, vol. 45, no. 7, pp. 769-773, 1992.

[28] J. Wöhrle, N. Merkle, V. Mailänder et al., "Results of intracoronary stem cell therapy after acute myocardial infarction," American Journal of Cardiology, vol. 105, no. 6, pp. 804-812, 2010.

[29] A. E. Denktas, H. V. Anderson, J. McCarthy, and R. W. Smalling, "Total ischemic time: the correct focus of attention for optimal ST-segment elevation myocardial infarction care," JACC: Cardiovascular Interventions, vol. 4, no. 6, pp. 599-604, 2011. 


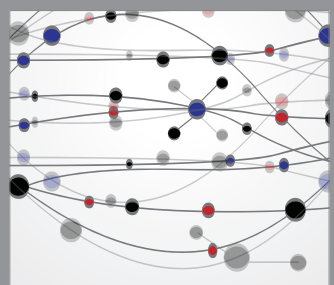

The Scientific World Journal
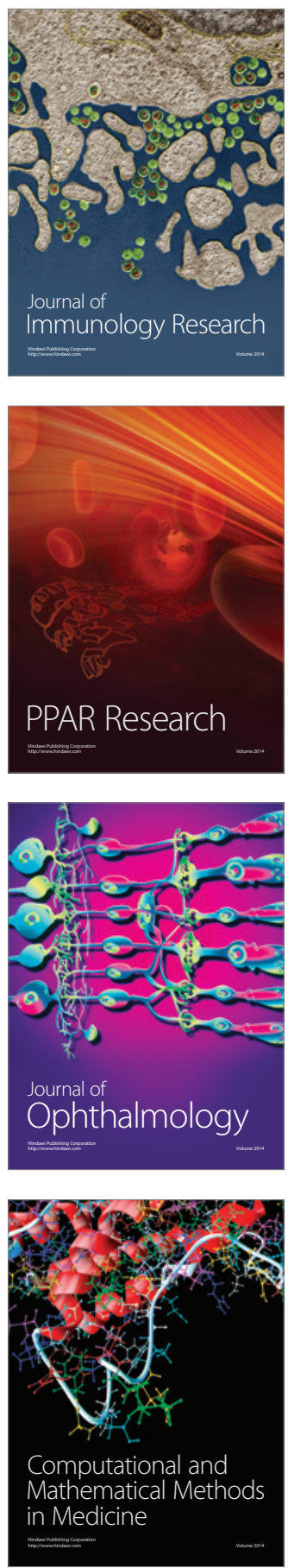

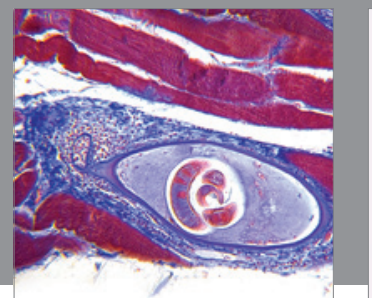

Gastroenterology

Research and Practice
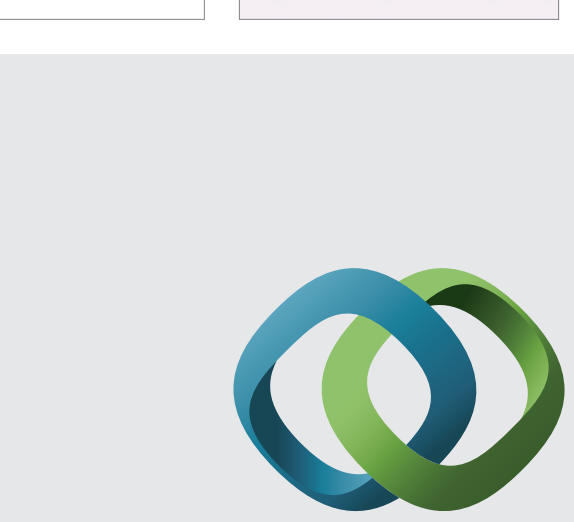

\section{Hindawi}

Submit your manuscripts at

http://www.hindawi.com
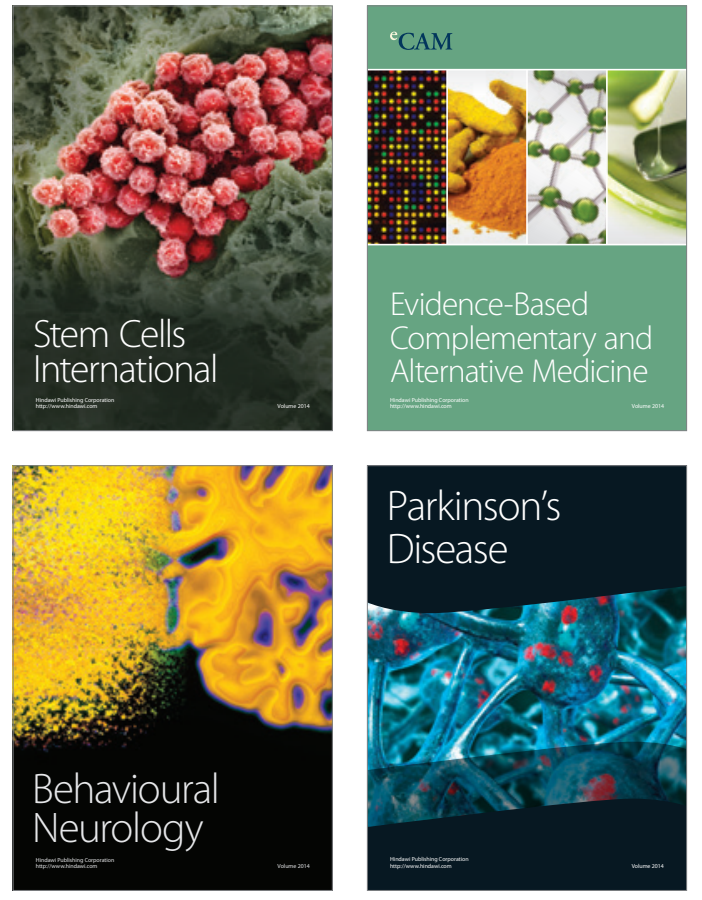
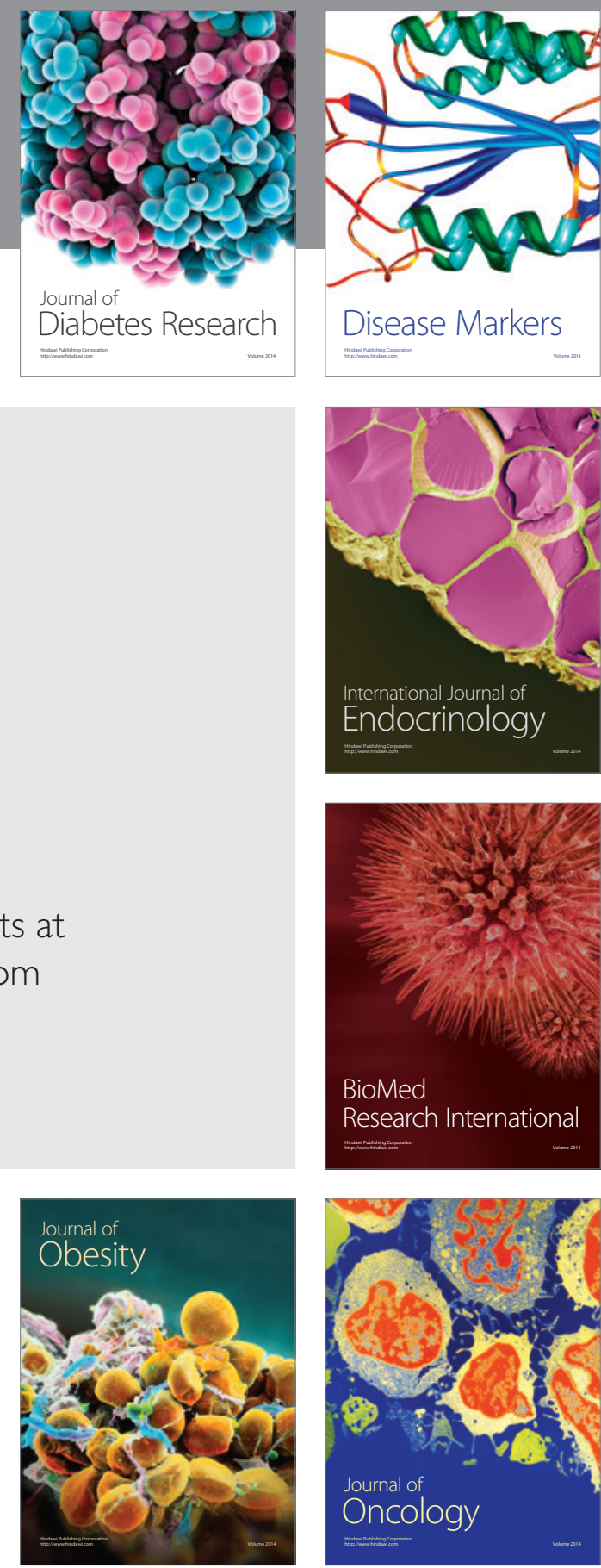

Disease Markers
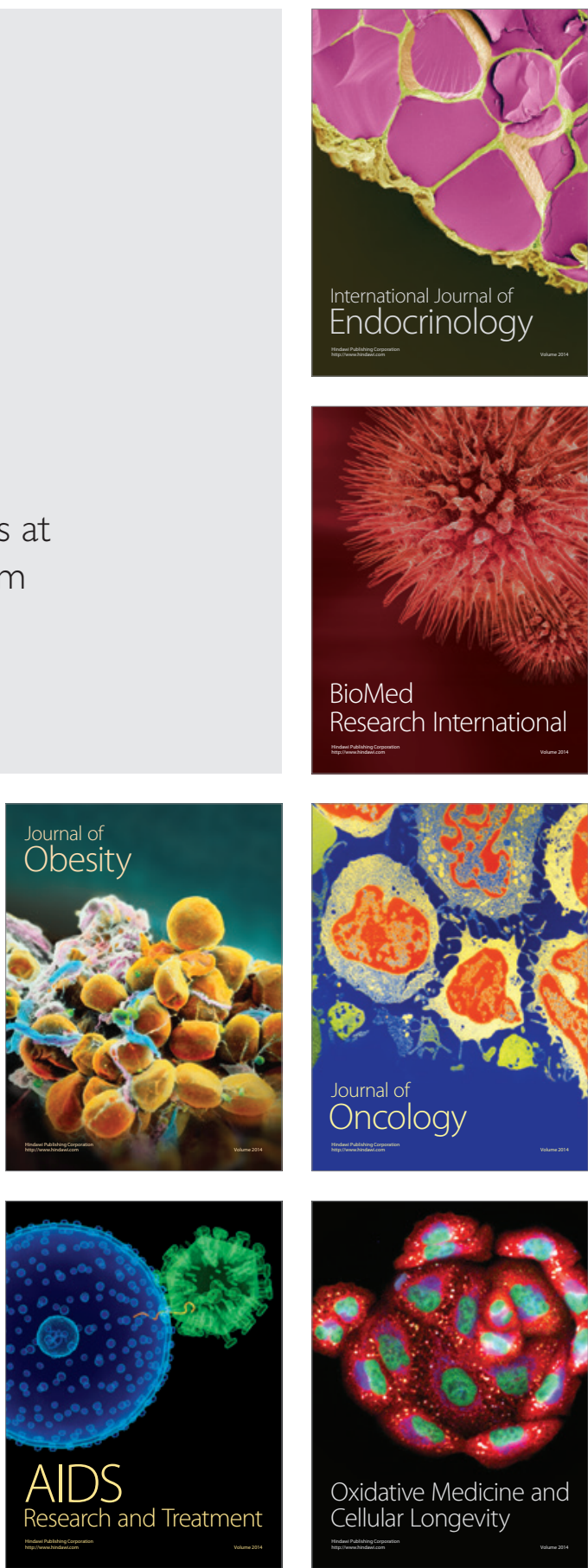